\title{
Bringing children's mental health "out of the shadows"
}

\author{
Kimberley McEwan, Charlotte Waddell, Jayne Barker
}

I n May 2006, the Honourable Michael Kirby, chair, and the Honourable Wilbert Keon, deputy chair of the Standing Senate Committee on Social Affairs, Science and Technology, issued their final report on mental health: Out of the Shadows at Last: Transforming Mental Health, Mental Illness and Addictions Services in Canada. ${ }^{1}$ Advocacy groups and professional associations across the country applaud the profile that this report gives to mental health. Yet the inherent focus on the recovery of adults with serious mental illness may be disappointing to those concerned with children's mental health.

Mental health is fundamental to children's social and emotional development, and therefore to well-being and function throughout their entire lifespan. However, an estimated $14 \%$ of children (or 800 ooo) in Canada experience mental disorders that cause clinically significant symptoms and impaired functioning. ${ }^{2}$ Anxiety, behavioural and depressive disorders are the most common mental disorders among children. ${ }^{3}$ Mental disorders frequently persist into adulthood and cause lifelong distress and disability. ${ }^{4}$ Given the associated human and fiscal costs, mental disorders are a leading health concern in Canadian children after infancy.

Although the Kirby-Keon report devotes a chapter to children, only Io of its II8 recommendations explicitly focus on young people - predominantly those with an existing mental disorder. Recommendations to improve mental health services to children and to move services into nonstigmatizing settings are irrefutably important, but in emphasis, decidedly "downstream": that is, they go into effect after problems are already entrenched. Recommendations that look "upstream" to where problems begin - that is, to promote social and emotional well-being and to prevent mental disorders early in life - are largely absent.

Out of the Shadows may reflect the predominant Canadian health policy emphasis. Nationally, health care expenditures comprise an estimated $95 \%$ of total health expenditures, with health care spending now totalling over \$I40 billion annually and with $44 \%$ of this spending being directed toward Canadians over the age of 65 years. ${ }^{5}$ In keeping with this emphasis, investments in children's mental health traditionally have $\infty$ gone largely toward specialized treatment services - yet, an estimated $75 \%$ of children with mental disorders do not access such services. ${ }^{2}$ Although many children do receive interventions in other settings such as primary care and schools, the capacity of these services to deliver effective treatments (such as cognitive-behavioural therapy) is limited. ${ }^{2}$ Given the limited reach of treatment services, continuing to invest mainly in treatment will likely have minimal impact on mental health of the population, ${ }^{6}$ in keeping with our increasing understanding that expansion of health care does not necessarily produce health. ${ }^{\text {? }}$

Mounting research evidence suggests that childhood is the optimal time to influence determinants of social and emotional well-being. ${ }^{8}$ Recent research also demonstrates that prevention programs in childhood can reduce the prevalence of mental disorders, while also addressing causal factors. ${ }^{9}$ For example, targeted parent training within disadvantaged families can significantly reduce subsequent prevalence of behavioural disorders in children, while also improving educational and social outcomes. ${ }^{9}$ In light of the research evidence and our increasing recognition of the importance of evidence-based policy-making, a public health strategy is needed, not only to provide effective treatment for children with established disorders, but also to promote the social and emotional well-being of all children, and to prevent mental disorders wherever possible. ${ }^{8}$

In their report, Senators Kirby and Keon proposed new transition funding to develop a community mental health system. Although children's needs are acknowledged, the principal funding components suggested, for adequate housing and a basket of community services, are again most germane to adults living with serious mental illness. The risk is that children's mental health - never prominent on the Canadian health-policy agenda and termed the "orphans' orphan" of health and health care by Senator Kirby himself - will be eclipsed by the immense needs in the realm of adult mental health.

The absence of a broader child-focused strategy may reflect a recognition that such a strategy is less appropriate for adults (given that many mental disorders begin in childhood) $)^{3,4}$ and conforms to the relative rarity of programs to promote mental health or prevent mental disorders for children in Canada. ${ }^{9}$ One exception is found in British Columbia, where the provincial government's 2003 Child and Youth Mental Health Plan ${ }^{10}$ has shifted policy investments "upstream." BC's Ministry of Children and Family Development is implementing this plan with new investments totalling $\$ 46$ million over 5 years. Four major goals are being pursued: reducing risk, building community capacity, improving treatment and support, and monitoring performance. As part of risk-reduction efforts, new prevention programs have been introduced. Most notable is FRIENDS, a universal program for the prevention of anxiety and depression, now being implemented in elementary schools across the province. Origin- 
ally developed in Australia, this program equips teachers to deliver a brief curriculum based on principles of cognitivebehavioural therapy to enhance coping and reduce disorder prevalence among children. ${ }^{9}$ Since FRIENDS was introduced in 2004, it has been implemented in 45 of BC's 60 school districts, with over 47000 children in grades 4 and 5 participating. The program's effectiveness is now under evaluation.

In $\mathrm{BC}, \mathrm{I} 5 \%$ of resources committed through the Child and Youth Mental Health Plan are targeted for disorder prevention and other risk-reduction initiatives. This is notable, given that $\mathrm{BC}$, like other Canadian jurisdictions, typically devotes only $5 \%$ of overall health spending to public health, including prevention activities. ${ }^{5}$ BC's prevention investments exemplify a new and deliberate shift from exclusively focusing "downstream" on treatment services toward a broader public-health strategy to reach greater numbers of people early in life.

Mental health begins in childhood. If we are to make a difference to the health of the population, new investments to ensure optimal social and emotional development in children and to prevent mental disorders should be much more prominent within any national agenda to transform the mental health system. Without question, adults with serious mental illness require a renewed mental health system. But the broader goal should be to improve the mental health of all Canadians. We cannot achieve this goal if we do not bring children's mental health "out of the shadows" as well. Investments in children's mental health are surely among the most important investments that any society can make.

This article has been peer reviewed.

Kimberley McEwan is Adjunct Professor and Charlotte Waddell is Associate Professor and Director with the Children's Health Policy Centre in the Faculty of Health Sciences, Simon Fraser University, Vancouver. Jayne Barker is Exec- utive Director of Child and Youth Mental Health with the British Columbia Ministry of Children and Family Development, Victoria, BC.

Competing interests: None declared.

Contributors: All authors contributed to conceiving and writing this commentary and have reviewed and approved the final draft.

\section{REFERENCES}

I. Kirby MJL, Keon WJ. Out of the shadows at last: transforming mental health, mental illness and addiction services in Canada. Ottawa: Standing Senate Committee on Social Affairs, Science and Technology; 2006. Available: www.parl.gc.ca/39/r/parlbus /commbus/senate/com-e/soci-e/rep-e/repo2mayo6-e.htm (accessed 2006 Dec 4).

2. Waddell C, McEwan K, Shepherd CA, et al. A public health strategy to improve the mental health of Canadian children. Can J Psychiatry 2005;50:226-33.

3. Costello EJ, Mustillo S, Erkanli A, et al. Prevalence and development of psychiatric disorders in childhood and adolescence. Arch Gen Psychiatry 2003;60:837-44.

4. Kessler RC, Berglund P, Demler O, et al. Lifetime prevalence and age-of-onset distributions of DSM-IV disorders in the National Comorbidity Survey Replication. Arch Gen Psychiatry 2005;62:593-602.

5. Canadian Institute for Health Information. National health expenditure trends, 1975-2005. Ottawa: Canadian Institute for Health Information; 2005.

6. Offord DR, Kraemer HC, Kazdin AE, et al. Lowering the burden of suffering from child psychiatric disorder: trade-offs among clinical, targeted and universal interventions. J Am Acad Child Adolesc Psychiatry 1998;37:686-94.

7. Evans RG, Stoddart GL. Producing health, consuming health care. In: Barer ML Marmor TR, editors. Why are some people healthy and others not? The determinants of health of populations. New York: Aldine de Gruyte; 1994. p 27-64.

8. Willms JD, ed. Vulnerable children. Edmonton: University of Alberta Press; 2002.

9. Waddell C, Hua JM, Garland O, et al. Preventing mental disorders in children: a systematic review to inform policy-making. Can J Public Health 2007;98. In press.

Io. Ministry of Children and Family Development. Child and youth mental health plan for British Columbia. Victoria: British Columbia Ministry of Children and Family Development; 2003. Available: www.mcf.gov.bc.ca/mental_health/mh_publications /cymh_plan.pdf (accessed 2006 Dec 4).

Correspondence to: Kimberley McEwan, Children's Health Policy Centre, Faculty of Health Sciences, Simon Fraser University, 515 West Hastings Street, Rm. 7248, Vancouver BC V6B 5K3; chpcom@sfu.ca 